\title{
A sabedoria bárbara e os limites da helenização: o mundo helenístico de Arnaldo Momigliano*
}

\author{
Alien Wisdom and the Limits of Hellenization: Arnaldo Momigliano's \\ Hellenistic World
}

\author{
Thiago do Amaral Biazotto \\ thiago_a_b@yahoo.com.br \\ Mestrando \\ Universidade Estadual de Campinas \\ Rua Cora Coralina, s/n - Cidade Universitária Zeferino Vaz \\ 13083-970 - Campinas - SP \\ Brasil \\ Pedro Paulo Abreu Funari \\ ppfunari@uol.com.br \\ Professor titular \\ Universidade Estadual de Campinas \\ Rua Cora Coralina, s/n - Cidade Universitária Zeferino Vaz \\ 13083-970 - Campinas - SP \\ Brasil
}

\section{Resumo}

Neste artigo busca-se analisar a obra do historiador italiano Arnaldo Momigliano (1908-1987), em particular no que se refere à abordagem dada por ele às interações culturais durante 0 período helenístico (323-30 a. C.). Será argumentado que as interpretações de Momigliano sobre o referido período estavam, em grande medida, marcadas por sua forte identidade judaica, ainda mais pelo fato de Os Limites da Helenização (Alien Wisdom: The Limits of Hellenization [1975]) - sua principal obra sobre o assunto - ter sido publicada sob os ecos dos ataques da Síria e do Egito ao Estado de Israel. Desse modo, busca-se problematizar a produção de Momigliano, demonstrado como o cenário político e identitário influiu no trabalho do historiador.

\section{Palavras-chave}

Arnaldo Momigliano; Helenismo; Historiografia.

\begin{abstract}
This article analyzes the scholarly work of Italian historian Arnaldo Momigliano, particularly his approach to cultural interaction during the Hellenistic period (323-30 BC). It asserts that Momigliano's interpretations about the period were largely marked by his strong Jewish identity. This is particularly true considering that the book Alien Wisdom: the limits of Hellenization (1975) - his major work on the subject - was published in the wake of the then recent attacks by Syria and Egypt against Israel. The article seeks, thus, to discuss Momigliano's views by demonstrating how this historian's work was tributary of his political and identity scene.
\end{abstract}

Keywords

Arnaldo Momigliano; Hellenism; Historiography.

Recebido em: 28/2/2014

Aprovado em: 30/6/2014

* Pesquisa realizada com o financiamento do Conselho Nacional de Desenvolvimento Científico e Tecnológico - CNPq. 
Nascido em 1908, Arnaldo Momigliano (1908-1987) é talvez o mais profícuo estudioso do mundo antigo do século passado. Dono de erudição virtualmente ilimitada, debruçou-se sobre um inesgotável manancial de temas relativos à Antiguidade. Entretanto, atribui-se amiúde a Os Limites da Helenização o título de magnum opus de sua vasta bibiografia (BROWN 1988, p. 252). Umas das pioneiras em questionar o conceito de helenização, a obra lançada em 1975 vem à tona num momento histórico marcado, entre outros, por dois aspectos de grande relevância. Em primeiro lugar, a repercussão das ditas críticas póscoloniais, ${ }^{1}$ que tinham em sua linha de frente a atenção às diversidades de sexualidade, religiosidade ou práticas culturais encontradas em quaisquer grupos humanos (FUNARI; GARRAFFONI 2012, p. 3). Em segundo lugar, os ataques da Síria e do Egito ao Estado de Israel, de grande relevância para nossa análise pelo fato de Momigliano, como se verá mais adiante, nunca ter escondido sua fé judaica. Tendo isso em vista, neste artigo busca-se analisar a obra do historiador italiano no que se refere à abordagem dada por ele às interações culturais durante o período helenístico (323-30 a. C.), partindo da hipótese de que, sendo Momigliano um erudito que estabelecia relações "[...] entre as ideias e a realidade social, entre o tópico que estava sendo examinado e sua historiografia, entre o Mundo Antigo e o moderno, inclusive o nosso [...]" (FINLEY 1989, p. 76-77), parece ser plausível admitir que ele tenha recebido influxos das críticas pós-coloniais e, principalmente, que sua forte ligação com a tradição judaica também pode tê-lo instado a tingir com tons particularmente dramáticos a resistência dos judeus frente ao avanço da cultura grega durante o período supracitado.

\section{Breve recapitulação do conceito de helenização}

O conceito de helenização, citado no título da mais saudada obra de Momigliano, embora se refira a sociedades e culturas pretéritas, é de origem moderna e, portanto, possui data e local de nascimento definidos: durante o século XIX, no contexto de unificação do Estado alemão sob o espectro da Prússia, e reporta-nos aos escritos do historiador, filólogo e político Johann Gustav Droysen (1808-1884). Droysen era fervoroso defensor da unificação alemã sob as rédeas prussianas e chegou mesmo a tomar parte como parlamentar na Assembleia de Frankfurt. O erudito, ademais, foi responsável pela cunhagem do termo "helenismo" na Era Moderna, usado para se referir à cultura greco-macedônia que triunfou, com as armas das falanges, sobre as hordas asiáticas, afirmando a supremacia da civilização grega (DROYSEN 2010, p. 37). Droysen via em Alexandre e no helenismo figuras responsáveis por criar um império pujante e coeso, no interior do qual surgiria o conceito de helenização: a adoção dos apanágios culturais helênicos pelos vencidos. A primeira menção a tal

\footnotetext{
${ }_{1}^{1}$ Pode-se definir de maneira esquemática o pós-colonialismo como o movimento de independência em grande escala ocorrido em países da África e da Ásia após a $2^{a}$ Guerra Mundial. Em seu bojo, diversos intelectuais produziram trabalhos que buscavam dar voz às antigas colônias e, ademais, fugir do espectro eurocêntrico que marcava os estudos ligados às ciências humanas até então. Edward Said, graças ao clássico Orientalismo: o Oriente como invenção do Ocidente, publicado em 1978, é considerado o maior expoente desse movimento (GOSDEN 2004, p. 18).
} 
fenômeno dá-se com o uso do verbo "helenizar": "os asiáticos incorporados nas fileiras do grande exército iniciavam-se na disciplina macedônia e começavam lentamente a se helenizar" (DROYSEN 2010, p. 292). Ao entrarem em contato com a superioridade bélica e moral dos batalhões de Alexandre, os asiáticos passariam a incorporar os hábitos que regiam a vida dos greco-macedônios nos campos de batalha. O conceito de helenização que assim nasceu tornou-se deveras popular, e toda uma série de tomos foi escrita inspirada nas letras do prussiano (ALCOCK 1994, p. 171-188).

Todavia, a partir da segunda metade do século $X X$, esse conceito passou a ser criticado de forma sistemática pela historiografia. ${ }^{2}$ Entre aqueles que tomaram parte nesse movimento, além de Momigliano, pode-se citar Claire Préaux (1904-1979), que defendia uma separação entre gregos e orientais, negando interações culturais entre eles, ${ }^{3}$ e Edouard Will (1920-1997), para quem a ideia de helenização foi pensada a partir de um contexto em que as potências europeias traçavam analogias entre a sua expansão colonial e aquela promovida por Alexandre (Cf. WILL 1985, p. 273-301.). Momigliano, portanto, não se encontrava isolado, ainda que, talvez, entre os autores citados, seja aquele cujas críticas foram mais refinadas, o que pode explicar, ao menos em parte, a maior repercussão de sua obra. ${ }^{4}$ No atual estágio da discussão historiográfica, a ideia de helenização é usada com parcimônia, e, ademais, destaca-se a influência da cultura autóctone durante o período helenístico. ${ }^{5}$

Na sequência do artigo, serão apresentadas a vida e obra de Momigliano 246 para, depois, abordar suas críticas à helenização e mostrar de que forma sua identidade judaica influenciou seus escritos.

\section{A vida e os estudos de Momigliano}

Arnaldo Dante Momigliano nasceu no quinto dia de setembro de 1908, na cidade de Caraglio, província de Cuneo, norte da Itália. Oriundo de uma eminente linhagem judaica, ${ }^{6}$ iniciou seus estudos acadêmicos em 1925, na Faculdade de Letras da Universidade de Turim. Lá, tornou-se pupilo de outro luminar do estudo da Antiguidade na Itália, Gaetano De Sanctis, responsável por supervisionar a

\footnotetext{
2 Poder-se-ia mesmo voltar ao historiador inglês George Grote, que, em pleno século XIX, escreveu que, longe de tentar helenizar a Ásia, Alexandre tentava "asiatizar" a Grécia e a Macedônia. Contudo, parece que Grote era uma voz solitária num contexto ainda marcado pela visão do macedônio como um conquistador benévolo que tinha livrado a Ásia dos grilhões da tirania e do misticismo.

${ }^{3}$ A obra Le monde hellénistique. La Grèce et l'Orient de la mort d'Alexandre à la conquête romaine de la Grèce (323-146 av. J.-C.), lançada em dois tomos em 1978, é aquela em que as posições de Préaux são formuladas de modo mais sofisticado.

${ }^{4}$ É oportuno ressaltar que Momigliano admite que as críticas pós-coloniais eram relevantes em sua época: vide a passagem na qual ele assevera que a descolonização contribuiu para uma mudança de atenção no que se refere aos nativos e escravos, responsável por influenciar até mesmo uma reavaliação dos pensadores helenísticos. Cf. MOMIGLIANO 1994, p. 159.

5 Exemplo profícuo é a tese de doutoramento de Gralha (2009), na qual o autor defende que, no Egito ptolomaico, longe de haver helenização, verificava-se, antes, a manutenção de práticas culturais do período faraônico de maneira a legitimar o governo estrangeiro dos sucessores de Alexandre.

6 O irmão do avô paterno de Momigliano, Amadio, era profundo conhecedor da tradição judaica, e é quase certo que foi ele o responsável por introduzi-la no futuro historiador (WEINBERG 1991, p. 14). O compromisso de Momigliano com a identidade judaica foi marcante em toda sua produção, aspecto que será um pouco mais explorado ao longo deste artigo. Por ora, é salutar lembramos o emblemático episódio citado por Hübscher (2010, p. 47) em que Momigliano acusa o historiador americano Moses Finley de ter repudiado "sua excepcional hereditariedade judaica" pelo fato de este ter alterado seu sobrenome original - Finkelstein - no início da década de 1940.
} 
tesi di laurea do jovem piemontês. Defendido em 1929 e abordando o método de escrita do historiador grego Tucídides, esse primeiro trabalho, de acordo com Amorós (1997, p. 196) carregava certas características, como o rigor filológico, que acompanhariam Momigliano por toda a vida.

Em 1932, o piemontês começa a contribuir com a Enciclopedia Italiana, que tinha entre seus organizadores Benedetto Croce e - mais sintomático Giovanni Gentile (PATLAGEAN 1982, p. 1005). No mesmo ano, assume o cargo de professor de História Grega da Universidade de Roma em circunstâncias bastante insólitas: De Sanctis havia sido proscrito da cátedra um ano antes por ter se recusado a prestar o juramento fascista. Sem constrangimento algum, Momigliano apossou-se do antigo ofício de seu mentor, prestando, claro, o juramento, indispensável àqueles que se candidatavam a empregos públicos (DI DONATO 2011, p. n/d). Naturalmente, a relação entre ambos azedou, o que levou Momigliano a romper com os métodos de seu preceptor. O livro Filippo Il Macedone: saggio sulla storia greca del IV secolo a.C., publicado em 1934 pelo piemontês, apresenta uma visão sobre os gregos e a pólis bastante distinta daquela defendida por De Sanctis (GABBA 1988, p. 367 ). Mais do que isso: décadas mais tarde, Momigliano chega até a censurar seu velho mestre, afirmando que: "[...] o mesmo homem que não tinha dúvidas em perder tudo, opondo-se ao fascismo, estava incerto sobre a guerra na Etiópia e, mais ainda, sobre a Segunda Guerra Mundial" (MOMIGLIANO 1975a, p. 183-184 apud GARCIA QUINTELA 2005, p. 194, tradução nossa).7

Em 1936, Momigliano é apontado para a cátedra de História Romana, da Universidade de Turim, mas a publicação do Manifesto della razza italiana ${ }^{8}$ por parte do governo Mussolini fez com que ele fosse afastado de seu cargo. Em 1939, consegue exílio em Oxford, onde seu trabalho é reconhecido e saudado, ainda que seu sotaque tornasse seus seminários não tão concorridos, em que pese sua habilidade em escrever na língua de Shakespeare (MURRAY 1991, p. 62).

Com o fim da Guerra em 1945, recebe o título de doutor honoris causa por Oxford e faz viagem de regresso à Itália. Lá, é convidado por Croce a tomar assento como diretor do recém-fundado Instituto Italiano de Estudos Históricos, em Nápoles. Depois de muito ponderar, Momigliano declina da invitação e, ainda que tenha sido reempossado como professor em Turim, decide continuar a viver na Inglaterra. Em 1947, é admitido pela Universidade de Bristol como professor de História Antiga (DI DONATO 2001, p. n/d).

Em 1951, Momigliano assume a cátedra de História Antiga na University College London e, em 1964, na Scoula Normale Superiore, em Pisa. Começa a ser reconhecido por sua devoção à história da historiografia, tema pelo qual se tornou, nas palavras de Kagan (1992) "a principal autoridade em historiografia da Antiguidade em todo o mundo". Momigliano tentava deixar o mais claro possível seus métodos nessa área da história; para ele, não bastava apenas

\footnotetext{
7 No original: "the same man who had no doubt in loosing everything by opposing fascism, was uncertain about the war in Ethiopia and even more so about World War II".

${ }^{8}$ Promulgado em agosto de 1938, Manifesto della razza italiana propugnava as leis do regime fascista italiano, cassando a cidadania dos judeus e demonstrando a influência de Adolf Hitler sobre Benito Mussolini.
} 
estudar os autores para realizar um trabalho historiográfico bem feito. Antes, era fundamental conhecer com profundidade as fontes que esses autores usavam para embasar seus escritos. E, mais, segundo o autor, era necessário o compromisso com a verdade: "História da Historiografia, como qualquer outra pesquisa histórica, tem o propósito de distinguir verdade e falsidade" (MOMIGLIANO 1980, p. 31-32 apud CHRIST 1991, p. 11, tradução nossa). ${ }^{9}$ Contudo, ainda que o italiano defendesse com afinco a objetividade do conhecimento histórico, há quem considere que ele não somente deixava suas preocupações políticas e religiosas nas estrelinhas de seus escritos como chegava a lançar mão delas em suas avaliações dos trabalhos de outros estudiosos (BERTI 1989, p. 301).

Em terras britânicas, Momigliano contribuiu com verbetes no Oxford Classical Dictionary e na Encyclopaedia Britannica, além de ter recebido a honraria de Knight Commander of the Order of the British Empire, em 1974. Aposentado em 1975, assumiu o cargo de Alexander White Visiting Professor na Universidade de Chicago, onde ficaria até sua morte, ocorrida a primeiro de setembro de 1987.

Ainda que seu repertório de referências teóricas seja vasto, Murray (1991, p. 62) destaca como as principais a erudição italiana aprendida em sua juventude ${ }^{10}$ combinada ao respeito filológico herdado da Altertumswissenschaft alemã e à tradição filosófica de Benedetto Croce. Sua produção é de profunda erudição e extremamente difícil de classificar, pelo fato de optar mais por artigos e resenhas - publicou mais de setecentos escritos dessa natureza em suas seis décadas de atividade - do que por estudos de fôlego mais largo. Ademais, a infinidade de 248 temas sobre os quais se debruçou também complica a ordenação de sua obra. Não obstante, Amorós (1997, p. 195-199), destaca as seguintes temáticas como as lembradas com mais frequência no cabedal do piemontês: a história da historiografia, que tem em The Classical Foundations of Modern Historiography (1990) sua mais ilustre representante, a preocupação com temas ligados à paz e à liberdade em autores antigos e modernos - que parecem conectados à sua própria experiência como judeu italiano - e, por fim, o período helenístico e as interações culturais entre gregos e autóctones, cujos baluartes são os artigos J. G. Droysen: between Pagans and Jews (1970), The Fault of Greeks (1975) e o volume Alien Wisdom: The Limits of Hellenization (1975). Para os fins deste artigo, esses três textos serão de particular valia como fontes para verificar como Momigliano encarava o mundo nascido das conquistas de Alexandre em termos de interações culturais.

\section{Os limites da helenização e a sabedoria bárbara: o mundo helenístico de Arnaldo Momigliano}

Alien Wisdom: The Limits of Hellenization reúne as conferências proferidas por Momigliano na Universidade de Cambridge, em 1973, e no Bryn Mawr

\footnotetext{
${ }^{9}$ No original: "History of historiography, like any other historical research, has the purpose of discriminating between truth and falsehood".

10 Mesmo Peter Brown (1988), acadêmico de larga erudição, afirma que no primeiro contato que teve com Momigliano ficou extasiado com sua ilustração, tecendo, ademais, diversos elogios ao caráter do italiano, exaltados até mesmo para os padrões aduladores de rigueur de um texto em homenagem a um recém-falecido.
} 
College, em 1974, acrescidas de uma bibliografia específica para cada capítulo. Segundo Funari e Grillo (2014) o objetivo magno de Momigliano com o livro é investigar "como se deu o contato entre os gregos e os celtas, judeus e iranianos, constando que de um espaço cultural para outro as relações foram diversas, variando tanto na intensidade quanto no impacto da presença grega". Com esse norte, veremos de que forma Momigliano encarava as relações culturais durante o período helenístico, tendo por base o volume e os artigos supracitados.

Para Momigliano, o acontecimento de primeira grandeza durante as conquistas de Alexandre foi a descoberta, da parte dos greco-macedônios, de povos até então obscuros, quais sejam os romanos, os judeus e os celtas. Mesmos os persas, familiares desde tempos idos, haviam passado por grandes mudanças, tendo o profeta Zoroastro substituído o monarca Ciro como figura mais ilustre (MOMIGLIANO 1991, p. 10). Já o Egito, ovacionado desde Heródoto, tinha sido de tal forma dominado que sua cultura nativa tinha "declinado" sob os greco-macedônios, fazendo com que suas imagens se limitassem àquelas de um misticismo extravagante previamente conhecido (MOMIGLIANO 1991, p. 11). Cartago, arrasada por Roma durante as Guerras Púnicas (264-146 a. C.), tinha chegado a contrair algumas alianças com pensadores helênicos, mas não chegara a contribuir de maneira satisfatória para o edifício cultural do período helenístico (MOMIGLIANO 1991, p. 12). A expansão territorial promovida pelas falanges alexandrinas, assim, teria fomentado uma intensa curiosidade nos gregos a respeito dessas populações, fazendo com que eles passassem a avaliar seus traços culturais cotejando-os aos dos nativos, assimilando, rejeitando e adaptando as singularidades com as quais se defrontavam. É esta a força motriz por trás do texto de Momigliano (1991 p. 13): "O que desejo verificar é como os gregos vieram a conhecer e avaliar esses grupos de não-gregos em relação à sua própria cultura e civilização".

Tão logo tomaram ciência da pujança intelectual que havia ao seu redor, os helenos passam a desenvolver o conceito que o estudioso italiano chama de "sabedoria bárbara": "A noção de um saber bárbaro conquistou estabilidade e aceitação entre aqueles que se consideravam gregos" (MOMIGLIANO 1991, p. 14). Essa noção se relacionava à necessidade que os gregos sentiam de "estudar as singularidades dos estrangeiros" (MOMIGLIANO 1991, p. 71). Nos séculos V e IV a. C., já havia entre eles a vaga consciência de que "sábios do Oriente" poderiam dissertar sobre a natureza humana. Mesmo o grande estagirita Aristóteles, preceptor de Alexandre, tinha alguma curiosidade sobre um certo "saber do Oriente" (MOMIGLIANO 1991, p. 78). Durante o período helenístico, contudo, a ideia de "sabedoria bárbara" cresceu de maneira assombrosa, fazendo com que figuras como as de Hermes Trimegisto, Zoroastro e Abraão exercessem notável influência com suas próprias doutrinas, desde que fossem professadas em grego (MOMIGLIANO 1991, p. 14).

Do que foi anunciado, já é possível perceber uma das maneiras como Momigliano critica a helenização: partindo da hipótese de que pensadores de origem não-grega, por meio de concepções filosóficas sofisticadas, estabeleceram-se e se tornaram percucientes na cultura do período helenístico. 
O interesse que havia na doutrina de Zoroastro, por exemplo, atestaria que as relações entre gregos e locais não estavam restritas à assimilação das práticas helênicas pelos autóctones. A noção de "saberes bárbaros", portanto, reduz a tese da helenização à medida que esses saberes foram incorporados à cultura grega conforme fosse o desejo dos helenos.

Maior que o intuito de diminuir a pujança da cultura grega - afinal, a língua dos helenos continuava universal durante o período helenístico (MOMIGLIANO 1991 , p. 15) -, o ponto principal para o italiano reside na grande curiosidade que os nativos da Hélade possuíam em relação àqueles descobertos durante o referido período. A curiosidade por essas novas culturas dotadas do "saber bárbaro" foi de tamanha magnitude que seu legado é sentido até os tempos hodiernos:

A Pérsia, a Mesopotâmia e o Egito se mantêm mais ou menos onde a erudição helenística os colocou como detentores do saber bárbaro. Ainda se dá lugar de destaque em nossos compêndios aos fenícios, e em particular aos cartagineses, por suas instituições e colonização, porque os gregos se reconheciam nessas coisas (MOMIGLIANO 1991, p. 17).

Não seria exagerado, portanto, afirmar que o "saber bárbaro" se tornou o "saber sobre o bárbaro", embora - aos menos para os gregos helenísticos de Momigliano - os ditos bárbaros não fossem tão bárbaros assim. Essa posição fica clara quando o historiador, na última página de Os limites da helenização, afirma que, tão logo os helenos começaram a se dar conta de toda a exuberância intelectual que os cercava, passaram a desconfiar de seus próprios saberes (MOMIGLIANO 1991, p. 132).

Desse modo, o historiador italiano opta pela expressão "civilização helenística" para aludir ao mundo nascido das conquistas de Alexandre. Trata-se de uma civilização nova, caracterizada não somente pelo êxito da cultura grega sobre os locais, mas pela miríade de relações culturais desenvolvidas em seu âmago. Eis o mundo enunciado por Momigliano (1991, p. 13-14):

A civilização helenística permaneceu grega na língua, nos costumes e,
sobretudo, na consciência de si mesma. [...] Isso significou que judeus,
romanos, egípcios, fenícios, babilônios e até indianos [...] se inseriram
na literatura grega com suas próprias colaborações [...]. No panteão
grego foram admitidos mais deuses estrangeiros do que em qualquer
época desde a pré-história [...]. Era um sincretismo assimétrico que
foi particularmente bem sucedido na Itália (Etrúria e Roma), deixou
sua marca em Cartago, na Síria e no Egito, foi mal sucedido na Judéia,
bastante insignificante na Mesopotâmia e afetou pelo menos a iconografia
senão a essência da religião indiana por meio da arte gândora.

A ideia de civilização helenística partia das discordâncias que Momigliano nutria abertamente em relação à obra de Droysen. Em artigo de título "J. G. Droysen between Greeks and Jews" (J. G. Droysen entre gregos e judeus), o italiano dá o devido crédito ao prussiano como formulador do termo "helenismo" no mundo moderno (MOMIGLIANO 1994, p. 149). Entretanto, Momigliano não se furta a criticar o fato de Droysen traçar analogias explícitas entre a Macedônia e a 
Prússia, fazendo com que o germânico propugnasse a tese de uma cultura grega exultando sobre o Oriente que não correspondia à realidade (MOMIGLIANO 1994, p. 158). A solução encontrada por Momigliano foi propor o termo "civilização helenística", expressão que alberga não apenas recortes cronológicos ou espaciais, mas, sobretudo, culturais. Essa elocução encontra ecos no artigo "The Fault of Greeks" (A culpa dos gregos), quando Momigliano propõe: "A noção de civilização helenística define tanto tempo (323-30 a. C.) quanto espaço (zona do Mediterrâneo) no qual essas três culturas convergiam e começaram a reagir uma à outra" (MOMIGLIANO 1975, p. 10-11, tradução nossa ${ }^{11}$ ).

As três culturas acima mencionadas por Momigliano são a grega, a romana e a judaica, sendo que as últimas tinham em comum o fato de não terem dúvida alguma sobre a superioridade de seus respectivos modos de vida em relação àquele dos gregos (MOMIGLIANO 1975, p. 12), o que, claro, depõe contra a tese de que teriam sido helenizadas. Por isso, na sequência do texto, serão apresentadas as formas pelas quais Momigliano via as respostas de romanos e judeus ao avanço da cultura grega.

\section{Resistência à helenização: as relações entre as culturas grega, romana e judaica no entendimento de Momigliano}

Momigliano considerava que o maior poderio bélico das forças de Roma fomentou em seus habitantes a sensação de superioridade em relação aos gregos, também nutrida por estes ao menos desde quando os exércitos de Pirro foram dizimados (MOMIGLIANO 1991, p. 20). Esse sentimento de primazia fez com que sua população passasse a haurir da cultura grega apenas aquilo que interessasse a seus próprios anseios, às vezes até pagando pelos saberes helênicos, ou nem isso, uma vez que não era raro ver sábios gregos escravizados pelos romanos (MOMIGLIANO 1991, p. 17). Sendo assim, a aristocracia de Roma achou por bem aprender o idioma grego tendo em vista um projeto imperial já em curso. Partindo disso, fica cristalino como Momigliano vê uma helenização circunscrita por uma empresa política, no caso romano, inexpugnável: a construção de um império extraordinário. Em suma, "os intelectuais gregos e romanos tiveram de aprender que em Roma a helenização subentendia respeito pela ordem dominante" (MOMIGLIANO 1991, p. 24).

Um caso emblemático era o do historiador e geógrafo Políbio. Nascido em Megalópolis, na Arcádia, Políbio foi tomado como refém pelos romanos em 167 a. C., mas - em virtude de sua notável ilustração - acabou acolhido e respeitado. Vivendo no seio da sociedade romana, não se defrontou com qualquer surpresa, pois lá "[...] encontrou pessoas que não diferiam dos gregos instruídos em interesses, ideias e reações emocionais" (MOMIGLIANO 1991, p. 28). Contudo, a difusão da cultura da Hélade nas terras fundadas por Rômulo aparece mais uma vez condicionada à vontade dos romanos de se instruírem com as experiências gregas, que Ihes dava uma gigantesca vantagem: "[...] a 
superioridade que os líderes romanos alcançaram pelo simples fato de poderem falar em grego e pensar em grego, ao passo que os líderes gregos necessitavam de intérpretes para entender o latim" (MOMIGLIANO 1991, p. 40). Ademais, essa adoção se dava pari passu à criação de "uma literatura nacional, autoconfiante e agressiva" (MOMIGLIANO 1991, p. 22) na qual Políbio tomava parte criando em seus escritos "uma atmosfera em que as conquistas romanas se tornavam fáceis de compreender e difíceis de contestar" (MOMIGLIANO 1991, p. 31).

Ao proceder assim, Momigliano reduz a helenização uma vez mais, agora ao apresentar um erudito grego não preocupado em disseminar sua cultura nativa, mas em articular um dialogo entre seus conterrâneos e os romanos de maneira a "explicar aos gregos por que os romanos venceram e explicar aos romanos o significado e as condições de sua própria vitória" (MOMIGLIANO 1991, p. 33). Um dos conselhos dado por Políbio, num admirável exercício de alteridade, versava sobre os perigos que os romanos correriam caso não debelassem suas sublevações internas (MOMIGLIANO 1991, p. 34).

Ainda que críticas possam ser feitas pelo fato de Momigliano sustentar sua argumentação quase inteiramente nas deduções do aristocrático Políbio - que, decerto, confabulava apenas com uma minúscula elite letrada -, não deixa de serem dignas de registro as discordâncias que o piemontês nutria em relação a uma incontestável propagação da cultura grega. Além disso, as interpretações de Momigliano de um Políbio absorvido de modo tal pela cultura romana que seria incapaz de traduzi-la em termos gregos - quase como se tivesse sido romanizado - têm sofrido críticas por parte da historiografia moderna. ${ }^{12}$

Já dissertar acerca da relação entre judeus e gregos, por sua vez, apresenta um desafio por conta do comprometimento de Momigliano com sua identidade judaica, aspecto que será mais explorado na próxima seção deste artigo. Por ora, cumpre ressaltar que, para o piemontês, os judeus estiveram desde sempre "convencidos de sua superioridade" (MOMIGLIANO 1991, p. 16). De partida, Momigliano afirma que os judeus eram conhecidos, ainda que de forma superficial, pelos gregos antes do advento de Alexandre, embora fossem ignorados nos registros escritos (MOMIGLIANO 1991, p. 73). De igual modo, não havia grande ciência dos helenos por parte dos semitas, embora a ignorância destes em relação àqueles fosse menor, em virtude de os gregos fazerem comércio na Palestina (MOMIGLIANO 1991, p. 75-76). Mesmo esse quadro de distanciamento mútuo não desencoraja Momigliano a traçar diversos paralelos entre o desenvolvimento das duas civilizações, talvez a sentenciar que a civilização ocidental é devedora da cultura judaica tanto ou mais quanto o é da cultura grega:

\footnotetext{
12 Texto ilustrativo é "Interpretando el mundo romano: etnografía, público y cultura griega en las 'Historias' de Polibio", de Moreno Leoni. O autor posiciona-se contra a visão do Políbio de Momigliano, apresentando estratégias discursivas usadas pelo historiador arcadiano na investida de criar uma alteridade entre ele e os romanos. Um exemplo seria a narração a respeito do saque de Cartago Nova, na qual Políbio disserta sobre o butim como uma prática tipicamente romana, mas, e ao mesmo tempo, deixando claro sua distância em relação a ela, uma vez que ela não era comum entre os gregos. Leoni questiona mesmo o "efeito prático" do trabalho de Políbio, uma vez que Tito Lívio, historiador que atuara já durante o principado, usa de seus relatos de modo parcimonioso, muitas vezes criando novos sentidos a partir das alocuções do arcadiano. Cf. MORENO LEONI 2012.
} 
O quadro das nações em Gênesis 10 nos faz lembrar do mapa de Anaximandro; o Livro de Jó, provavelmente uma obra de exílio, tem sido muitas vezes comparado ao Prometeu, de Ésquilo [...] (os judeus) confiavam em Deus e em sua própria Lei. Para a mesma finalidade, os gregos confiavam nas próprias inteligências e iniciativa [...] (MOMIGLIANO 1991, p. 77).

Momigliano também admite que, à semelhança dos romanos, os judeus aprenderam o idioma e os costumes gregos como forma de comparar seu cabedal àquele dos helenos: "[...] tanto judeus quanto romanos decidiram aprender o idioma grego de modo a comparar seus próprios costumes com aqueles dos gregos e modelar sua vida intelectual em relação aos gregos" (MOMIGLIANO 1975, p. 13, tradução nossa). ${ }^{13}$ Assim, a partir de 300 a. C., os judeus começaram a se versar no idioma grego e, exprimindo suas doutrinas nele, tornaram-se ilustres, como eram os filósofos estoicos Zenão de Cício (333263 a. C.) e Crisipo de Soli (280-208 a. C.) (MOMIGLIANO 1991, p. 85). Um exemplo lapidar de como procediam os filósofos judeus no período helenístico é o de Aristóbulo de Paneas, sucessor de Fílon de Alexandre e responsável por uma alegoria em que Ptolomeu IV (181-145 a. C.) fazia incessantes perguntas sobre a Bíblia, instigado por seu conteúdo (MOMIGLIANO 1991, p. 86). Momigliano defende, por fim, que os judeus amiúde consideravam que o modus vivendi herdado de Moisés e Abraão era mais auspicioso do aquele apregoado por Homero e Heródoto (MOMIGLIANO 1975, p. 14-15). Em suma, para os judeus, era possível "afirmarem que haviam sido os mestres dos gregos devido à sua maior antiguidade" (MOMIGLIANO 1991, p. 86).

Não obstante, o engajamento de Momigliano com sua genealogia judaica parece mais peremptório quando o historiador discorre sobre as diferentes formas por meio das quais romanos e semitas resistiram ao avanço da helenização. Se, no caso dos primeiros, a oposição era comandada pela independência política e uma máquina militar incomparável, no caso dos judeus, a resistência era fruto de uma "mera obstinação da fé" (MOMIGLIANO 1991, p. 88). Como observou de modo perspicaz Starr (1976, p. 1079), quando Momigliano aborda os judeus em Os limites da helenização, adota um ponto de vista particular, como se estivesse falando sobre um ethos ao qual pertence. Isso, somado à discussão com Finley e a outros aspectos ainda mais relevantes que serão relatados a seguir, mostra algumas indicações do compromisso do historiador com sua identidade judaica.

\section{"Os judeus se mantiveram vivos pela mera obstinação na fé": por uma afirmação da identidade judaica nos escritos de Momigliano}

Stuart Hall (2005), teórico cultural jamaicano há pouco falecido, defende que as identidades sociais são fluidas, reconstruídas e afirmadas conforme as necessidades do tempo corrente. No caso de Momigliano, as impressões de Hall parecem bastante acertadas. Embora o historiador, conforme se viu, tenha 
sido expulso da Itália em função de sua ascendência judaica, sua posição como judeu nem sempre foi tão categórica, de modo que esta última parte do artigo tentará dar conta de explicar de que formas ela foi construída e como aparece refletida em seus registros.

Conforme recapitula Hübscher (2010, p. 52-53), Momigliano, em discurso proferido em 1977, afirmava que sua infância tinha sido cercada por uma tradição judaica, mas, de modo concomitante, por fortes raízes italianas, em virtude da fervorosa herança católica da vila onde nasceu. Parece imperativo que foram esses vínculos com os valores italianos que levaram Riccardo, pai de Momigliano, a se afiliar ao Partido Fascista, no qual exerceu cargos que iam de Fascio di Combattimento Del Comune di Caraglio (1923-1924) até comissário extraordinário (1929-1932). Ilda Levi, mãe do historiador, foi condecorada com medalha de bronze pelos serviços prestados como enfermeira durante a Primeira Guerra Mundial. Não por acaso, no vilarejo de Caraglio, lar dos abastados Momigliano, eles ficaram conhecidos pela bizarra pecha de "judeus fascistas".

Mesmo o próprio Arnaldo havia se filiado ao GUP (Gruppo Universitario Fascista) de Turim, em 1920, no grupo musical universitário. Esse vínculo, ainda que tênue, seria mantido nas décadas seguintes, até sua proscrição da Itália em função das leis de 1938. Quando já em terras britânicas, Momigliano dá uma declaração por escrito em que repudia quaisquer tentativas de associar seu nome à doutrina fascista. Entre os pontos levantados, encontra-se a publicação do jornal antifascista "Difesa Liberale" (1926), sua participação como articulista 2.54 no periódico "La Cultura", suprimido em 1933 devido ao seu caráter liberal, e a inabalável crença em ter proferido incontáveis aulas de "tendência abertamente liberal" (HÜBSCHER 2010, p. 55-56).

Ao mesmo tempo em que tenta refutar qualquer ranço fascista em sua juventude, Momigliano começa a dar ênfase à sua identidade judaica, aspecto bastante notado em seus estudos a respeito do período helenístico, escopo deste texto. Incidente capital foi sua violenta altercação com a obra de Droysen. Momigliano estava convencido de que a decisão do prussiano pouco escrever sobre a importância dos judeus para a fundação cultural da civilização helenística residia em dois pontos: a profunda ignorância da qual padecia o germânico a respeito da tradição literária judaica - e com o qual Momigliano (1994, p. 154) se mostrava indignado - e as profundas ambiguidades que Droysen nutria em relação àqueles que professavam a fé semita. $O$ italiano certificava que Droysen pertencia a um círculo intelectual constituído por diversos judeus convertidos ao protestantismo, entre os quais se encontrava até Marie Mendelheim, sua primeira esposa; entre eles, teria se estabelecido uma espécie de norma social que prescrevia o silêncio em relação às origens judaicas e ao passado (MOMIGLIANO 1994, p. 156-157). Por fim, Momigliano também se exaltava com a intervenção das convicções políticas de Droysen em sua obra, ainda mais pelo fato de ele ter abandando por completo o estudo do mundo antigo em favor da história moderna, em particular da Prússia, a partir de 1840.

Desse modo, parece ser factível admitir que a identidade judaica de Momigliano se manifesta de forma crescente em sua vida e obra. Se no início 
de sua trajetória, o historiador chegou até mesmo a se afiliar ao GUP de Turim e a prestar o juramento fascista de modo a tomar posse do cargo de professor em Roma, após seu banimento da Itália devido aos desmandos da tirania mussoliniana, Momigliano deu, como se viu acima, declarações bastante categóricas visando tanto a reafirmar sua ascendência judaica quanto a repudiar qualquer vestígio fascista em sua juventude. Mais do que isso: o tema do judaísmo no mundo antigo aparece de modo mais assíduo em seus estudos, muitas vezes carregando opiniões bastante fortes a respeito de historiadores que, claro, não davam o justo crédito à cultura hebraica, como foi o caso de seu artigo sobre Droysen, publicado originalmente em 1970. Entretanto, o pináculo desse processo aparece de forma mais nítida nas páginas d'Os limites da helenização - obra dedicada à memória de sua mãe, morta em um campo de concentração - , talvez em virtude dos diversos conflitos militares pelos quais passava o estado de Israel ao menos desde a Guerra dos Seis Dias e cujo fastígio foram os ataques da Síria e do Egito em 1973.

Em Alien Wisdom, ao analisar a situação dos judeus que se encontravam sob o jugo de Antíoco IV, entre 168 e 164 a. C., Momigliano narra com gigantesca dramaticidade a política de helenização implementada pelo soberano selêucida:

O Templo de Javé foi transformado em templo de Zeus Olímpico, os habitantes de Jerusalém foram denominados antioquianos e a misteriosa Acra, a fortaleza, foi ocupada por uma guarnição síria: práticas tradicionais judias, como a circuncisão e a observância dos sábados, foram proibidas. Desde tempo imemoriais era inaudita no mundo de fala grega uma tamanha interferência nos cultos ancestrais de uma nação (MOMIGLIANO 1991, p. 91, grifos nossos).

No excerto acima, é ostensiva a comoção de Momigliano em relação aos judeus em território selêucida, sufocados de forma horrenda por uma cultura helenística que transbordava indigência e esqualidez. Salta aos olhos a escolha pelo uso do termo "nação", em especial por Momigliano ter testemunhado o surgimento do Estado de Israel, em 1948, já na condição de intelectual de prestígio internacional. É ainda mais sintomática a classificação da rebelião macabeia revolta judaica contra a imposição da cultura grega estabelecida por Antíoco IV - como "uma guerra pela independência" (MOMIGLIANO 1991, p. 91).

Cumpre esclarecer que as conferências que dão origem ao livro foram proferidas em maio de 1973, em Cambridge, e revisadas em fevereiro-março de 1974, no Bryn Mawr College. Ao reuni-las na forma de livro, Momigliano objetivava "estimular a discussão a respeito de um assunto importante" (MOMIGLIANO 1991, p. 7). É importante salientar que sua publicação, em 1975, foi feita ainda sob os ecos dos ataques da Síria e do Egito ao Estado de Israel, em outubro de 1973, em pleno Yom Kippur, a data mais sagrada do calendário judaico e que Momigliano, a propósito, guardava rigorosamente. ${ }^{14}$ Claro que, conhecendo o modus operandi do historiador - que prezava pela erudição e pelo levantamento 
extensivo de fontes -, não se poderia afirmar que ele dissertaria sobre o tema simplesmente a reboque dos ataques supracitados, mesmo porque o judaísmo sempre esteve presente em sua obra. Ademais, as exposições preliminares que deram substância ao livro foram proferidas em março de 1973, ao passo que os ataques ocorreram em outubro. O que se defende é a atenção a dois aspectos: em primeiro lugar, a forma particularmente catastrófica com que o piemontês narra a condição dos judeus no período helenístico. Em segundo lugar, a opção de Momigliano por publicar o livro com tamanha urgência, talvez inspirado tanto pelos ataques quanto por sua necessidade de afirmar sua ascendência judaica na tentativa de dissipar as ambíguas relações que nutria com o fascismo em sua juventude, conforme visto acima.

Asfixiadas pelo bestial despotismo de Antíoco IV, a fé e a tradição ancestral dos judeus estava ameaçada por todos os lados. Segundo Momigliano, o livro bíblico de Daniel tinha na passagem "[...] há um domínio estrangeiro que trouxe consigo a contaminação" o "único testemunho contemporâneo do lado judeu" (MOMIGLIANO 1991, p. 100). Cercado de exércitos inclementes, prontos a massacrar sua fé, o povo judeu é tenaz, persistente, inflexível: sua resistência representa o "[...] repúdio ao helenismo [...] uma reafirmação da fidelidade da comunidade judia ao Deus de Abraão, Isaac e Jacó" (MOMIGLIANO 1991, p. 92). Sua obstinação é a dos "[...] judeus palestinos em defender a própria herança contra a tentativa de helenização em grande escala [...]" (MOMIGLIANO 1991, p. 107). A resistência judaica contra os ataques do helenismo fez com 256 que Antíoco IV baixasse um decreto para garantir que as suas leis voltassem a ser respeitadas. Momigliano acrescenta que combater de forma tão ferrenha em favor de suas tradições tornaria os judeus ainda mais devotados, fazendo nascer, nos termos do autor:

Uma nova devoção à Lei [...] uma regulamentação cada vez mais minuciosa das obrigações religiosas, uma meditação mais intensa sobre as relações entre a sabedoria divina e a fragilidade humana, e por fim, uma expectativa intermitente, mas muito real, das perturbações da Era Messiânica [que] reduziram o impacto dos costumes estrangeiros (MOMIGLIANO 1991, p. 103).

Impiedosas investidas estrangeiras. Uma resistência briosa sustentada sobremaneira pela fé. Um quadro de infortúnios e flagelos que se apresentam como intermináveis, mas que não levam à capitulação ou à desesperança. Levam, sim, a uma devoção cada vez mais inquebrantável. Se talvez seja exagerado afirmar que a substância dos escritos de Momigliano foi influenciada pela situação dos judeus em sua própria época, pelos motivos já apresentados, ao menos sua forma particularmente dramática de narrar os fatos parece ter sido motivada pelo episódio dos ataques a Israel, ainda mais pelo fato de o próprio historiador afirmar que suas primeiras conferências sobre o assunto foram revisadas antes da publicação em livro.

A propósito, é digna de registro a insistência de Momigliano em publicar urgentemente Os limites da helenização em forma de saltério, que, aliás, foi 
dedicado à memória de sua mãe, morta em 1943 num campo de concentração. É sabido que o piemontês deixava engavetados por anos a fio alguns de seus textos, que só veriam a luz do dia em seus famosos Contributi, por vezes publicados com anos de atraso em relação à data original de sua redação. Desse modo, por que Momigliano teria tamanha pressa em transformar seus papers em livro? E, mais, como esquecer as palavras do próprio piemontês, ditas originalmente em 1981, portanto pouco depois do lançamento d'Os limites da helenização? Em artigo no qual lança diatribes furiosas contra o historiador americano Hayden White - famoso por suas opiniões, digamos, polêmicas, a respeito da objetividade do conhecimento histórico e mesmo do Holocausto -, Momigliano sentencia: "Eu sou judeu e sei por experiência própria o preço que os judeus tinham e têm de pagar para serem judeus. Não estou coletando dados para fins acadêmicos quando tento entender o que levou os judeus a recusarem a assimilação a civilizações vizinhas" (MOMIGLIANO 1984, p. 54 apud WEINBERG 1991, p. 16, tradução nossa). ${ }^{15}$ Enfim, sendo Os limites da helenização a obra prima que é - como bem apontou o resenhista John Briscoe, "Momigliano nunca toca um assunto sem iluminá-lo" (1978, p. 110, tradução nossa) ${ }^{16}$ - , como menoscabar as palavras de Oscar Wilde: "todo o retrato pintado com sentimento retrata o artista e não o modelo" (1995, p. 11)?

\section{Considerações finais}

De acordo com o exposto, Momigliano possui visões peculiares a respeito das relações culturais durante o período helenístico, optando por uma abordagem mais multifacetada, tributária do conceito de "saber bárbaro". Momigliano conjectura que os gregos helenísticos ficaram boquiabertos com a exuberância intelectual que os cercava, fazendo com que no âmago de sua civilização houvesse uma série de relações culturais complexas.

As teses do italiano aparecem de forma mais clara quando vêm à tona as relações de romanos e judeus com o helenismo: enquanto os primeiros resistiram a ele em função da superioridade garantida por seu pungente aparelho militar, os seguidores da Lei de Moisés perseveraram em função de sua singular obstinação. Se, conforme apontam Silva e Feitosa (2009, p. 211), "[...] o historiador produz, com o seu ofício, espaços, tempos e práticas, do mesmo que ele próprio se encontra inserido em contextos e conjunturas que influenciam o tema em análise", parece ser válido indagar até que ponto o cenário político - marcado tanto pela emergência de movimentos sociais que objetivavam dar voz a grupos minoritários quanto pelos ataques da Síria e do Egito ao Estado de Israel - influenciaria Momigliano, que se encontrava cada vez mais imbuído da necessidade de afirmar sua identidade judaica. A esse respeito, Christ (1991, p. 11) considera como fio condutor de toda a obra de Momigliano a temática dos contatos entre culturas, religiões e civilizações, que remonta à

\footnotetext{
15 No original: "I am a Jew myself and I know from my own experience what price Jews had and have to pay to be Jews. I am not collecting facts for academic purpose when I try to understand what moved the Jews to refuse assimilation to surrounding civilizations".

16 No original: "Momigliano never touches a subject without illuminating it".
} 
sua juventude e que retorna de modo pungente na velhice, momento em que o italiano começa a notar de maneira mais clara as influências de sua vida em seu trabalho, aspecto também apontado por Bowersock (1991, p. 33) e que também corrobora a tese de que o italiano passou a afirmar sua identidade à medida que foi envelhecendo. Em publicação já ao final de sua vida, Momigliano afirma sem rodeios que: "Em certo sentido, na minha vida acadêmica eu não tenho feito outra coisa senão tentar entender o que eu devo tanto à casa judaica na qual cresci quanto à vila cristã-romana-celta na qual eu nasci" (MOMIGLIANO 1987, p. 432 apud CHRIST 1991, p. 5, tradução nossa). ${ }^{17}$ Talvez daí decorresse o interesse de Momigliano pelo período helenístico, momento no qual esses elementos - as culturas grega, romana, celta e muitas outras - se encontravam, conforme a sugestão de Weinberg (1991).

Na mesma ordem de ideias, Amóros (1997, p. 203) assevera que algumas das últimas linhas redigidas pelo italiano se encontram no novo prefácio à obra Filippo Il Macedone. Saggio sulla storia greca del IV secolo a. C., reimpressa em 1987. Nele, o historiador italiano admite que, na época da publicação original (1934), estava por demais preocupado com sua liberdade política e religiosa, aspecto que aparece nas entrelinhas de seus relatos sobre o caolho monarca.

Diante dessas demonstrações, parece ser factível afirmar que a preocupação do historiador italiano com sua identidade judaica é um aspecto que perfaz toda sua obra, que percorre toda sua vida. E foi quando ela chegou ao fim que Momigliano deu seu mais peremptório veredicto. Na inscrição de sua lápide, 258 ditada pelo próprio e citada por Di Donato, lê-se o seguinte:

Aqui repousa Arnaldo Dante Momigliano (1908-1987), professor de História Antiga das Universidades de Turim, de Londres, de Chicago e da Escola Normal Superior de Pisa. A sua fé foi o livre pensamento, sem ódio e sem dogma; mas amou, com afeto filial, a tradição hebraica dos antepassados e aqui quis consigo, reunidos na recordação, os genitores Riccardo e Ilda Momigliano, mortos em terra germânica, em novembro de 1943, por tresloucado ódio racial (DI DONATO 2011, p. n/d, tradução nossa). ${ }^{18}$

\section{Referências bibliográficas}

ALCOCK, Susan. Breaking up the Hellenistic world: survey and society. In: MORRIS, Ian. Classical Greece: ancient histories and modern archaeologies. New York: Cambridge University Press, 1994, p. 171- 190. AMORÓS, Pedro. Notas sobre Arnaldo Momigliano: la tradición histórica italiana.

Panta Rei, p. 95-103, 1997.

BERTI, Silvia. Autobiografia, storicismo e verità storica. Rivista storica italiana, n. 100, p. 297-312, 1988.

\footnotetext{
${ }_{17}$ No original: "In a sense, in my scholarly life I have done nothing else but to try to understand what I owe both to the Jewish house in which I was brought up and to the Christian-Roman-Celtic village in which I was born". ${ }_{18}$ No original: "Qui riposa Arnaldo Dante Momigliano (1908-1987) professore di storia antica nelle Università di Torino e di Londra e Chicago e nella Scuola Normale Superiore di Pisa. La sua fede fu il libero pensiero senza odio e senza dogma ma amò di affetto filiale la tradizione ebraica dei padri e qui volle seco congiunti nel ricordo i genitori Riccardo e Ilda Momigliano uccisi in terra germanica nel novembre 1943 per folle odio di razza".
} 
BOWERSOCK, Glen. Momigliano's Quest for the Person. History and Theory, v. 30, n. 4, p. 27-36, 1991.

BRISCOE, John. Review of Alien Wisdom. The Limits of Hellenization by Arnaldo Momigliano. The Classical Review, New Series, v. 28, n. 1, p. 109-110, 1978.

BROWN, Peter. IN MEMORIAM: Remembering Arnaldo. The American Scholar, v. 57, n. 2, p. 251-252, 1988.

DI DONATO, Riccardo. MOMIGLIANO, Arnaldo Dante. In: Dizionario Biografico degli Italiani, v. 75, 2011, p. n/d. Disponível em: http://www.treccani.it/ enciclopedia/arnaldo-dante-momigliano_(Dizionario-Biografico)/. Acesso em: 13 maio 2014.

DROYSEN, Johann Gustav. Alexandre: o grande. Rio de Janeiro: Contraponto, 2010 [1833].

FEITOSA, Lourdes Conde; SILVA, Glaydson José da. O Mundo Antigo sob lentes contemporâneas. In: FUNARI, Pedro Paulo Abreu; SILVA, Maria Aparecida de Oliveira (orgs.). Política e identidade no Mundo Antigo. São Paulo: Annablume, 2009, p. 209-250.

FINLEY, Moses. A tradição histórica: os Contributi de Arnaldo Momigliano. In: Uso e abuso da história. São Paulo: Martins Fontes, 1989 [1975], p. 75-87.

FUNARI, P. P. A.; GARRAFFONI, Renata Senna. Discussing acculturation as an interpretive model: Romanisation as a case-study. 2012, p. 1-7. (Manuscrito inédito usado com autorização dos autores).

FUNARI, Pedro P. A.; GRILLO, José G. C. Os conceitos de helenização e de romanização e a construção de uma Antiguidade Clássica. In: ALMEIDA, Néri de Barros; NEMI, Ana; PINHIEIRO, Rossana Alves Baptista (orgs.). A construção da narrativa histórica: séculos XIX e XX. Campinas; São Paulo: Unicamp; Fap-Unifesp, 2014, p. 205-214.

GABBA, Emilio. Aspetti della storiografia di M. Rivista Storica Italiana, n. 100, p. 362-80, 1988.

GARCÍA QUINTELA, Marco. Dúmezil, Momigliano, Bloch, between politics and historiography. Historie des études indo-européennes, p. 187-205, 2002-2005.

GOSDEN, Chris. Archaeology and colonialism: cultural contact from 5000 B.C. to the present. Cambridge, UK; New York, NY: Cambridge University Press, 2004.

GRALHA, Julio. A legitimidade do poder no Egito ptolomaico: cultura material e práticas mágico-religiosas. 276 p., 2009. Tese (Doutorado em História). Programa de Pós-Graduação em História, Instituto de Filosofia e Ciências Humanas, Universidade Estadual de Campinas. Campinas, 2009. 
HALL, Stuart. A identidade cultural na pós-modernidade. Rio de Janeiro: DP\&A, 2005.

HÜBSCHER, Bruno. Arnaldo Momigliano: história da historiografia e do mundo antigo. 111 p., 2010. Dissertação (Mestrado em História). Programa de Pós-Graduação em História, Faculdade de Filosofia, Letras e Ciências Humanas Universidade de São Paulo. São Paulo, 2010.

KAGAN, Donald. Arnaldo Momigliano and the human sources of history. The New Criterion, v. 10, n. 7, 1992. Disponível em: http://www.newcriterion.com/ articles.cfm/The-human-sources-of-history-4530. Acesso em: 22 fev. 2014.

MOMIGLIANO, Arnaldo. J. G. Droysen between Greeks and Jews. In: BOWERSOCK, Glen; CORNELL, Tim (orgs.) A. D. Momigliano: studies on modern scholarship. Berkeley: University of California, 1994, p. 147-161.

. Os limites da helenização. Rio de Janeiro: Jorge Zahar Editor, 1991 [1975].

- Ottavo contributo alla storia degli studi classici e del mondo antico. Roma: Edizioni di Storia e Letteratura, 1987.

. Settimo contributo alla storia degli studi classici e del mondo antico. Roma: Edizioni di Storia e Letteratura, 1984.

- Sesto contributo alla storia degli studi classici e del mondo antico. Roma: Edizioni di Storia e Letteratura, 1980

- Quinto contributo alla storia degli studi classici e del mondo antico. Roma: Edizioni di Storia e Letteratura, 1975a.

. The Fault of Greeks. Daedalus, v. 104, n. 2, p. 9-19, 1975.

MORENO LEONI, Álvaro. "Interpretando el mundo romano: etnografía, público y cultura griega en las 'Historias' de Polibio". Gerión, n. 30, p. 63-90, 2012.

MURRAY, Oswyn. Arnaldo Momigliano in England. History and Theory, v. 30, n. 4, Beiheft 30, p. 49-64, 1991.

PATLAGEAN, Evelyne. Les Contributi d'Arnaldo Momigliano: portrait d'un historien dans ses paysages. Annales, Historie, Sciences Sociales, 37e Année, p. 1004-1013, Sep-Dec. 1982.

PRÉAUX, Claire. Le monde hellénistique. La Grèce et I'Orient de la mort d'Alexandre à la conquête romaine de la Grèce (323-146 av. J.-C.). Paris: Presses Universitaires de France, 1978 (2 vol.)

STARR, Chester. Alien Wisdom. The Limits of Hellenization by Arnaldo Momigliano. The American Historical Review, v. 81, n. 5, p. 1079-1080, 1976.

WEINBERG, Joanna. Where Three Civilizations Meet. History and Theory, v. 30, n. 4, p. 13-26, 1991.

WILDE, Oscar. O Retrato de Dorian Gray. Rio de Janeiro: Ediouro, 1995 [1891]. 
WILL, Eduoard. Por une anthropologie coloniale du monde hellénistique. In: WILLIAM John ; OBER, Josiah (eds.) The Craft of the Ancient Historian: Essays in honour of Chester G. Starr. New York ; London: University Press of America, 1985, p. 273-301. 